\title{
Factors associated with non-adherence to prescribed iron supplement use: a study with pregnant women in the city of Rio de Janeiro
}

\author{
Roberta Pereira Niquini 1 \\ Sonia Duarte de Azevedo Bittencourt 2 \\ Elisa Maria de Aquino Lacerda 3 \\ Cláudia Saunders 4 \\ Maria do Carmo Leal 5 \\ ${ }^{1}$ Instituto Federal de Educação Ciência e Tecnologia do Rio de Janeiro. Campus Realengo. Rua Carlos Wenceslau, 343. Realengo. Rio de Janeiro, RJ, Brasil. CEP: 21.715- \\ 000. E-mail: roberta.niquini@ifrj.edu.br \\ 2,5 Departamento de Epidemiologia e Métodos Quantitativos em Saúde. ENSP-Fiocruz. Rio de Janeiro, RJ, Brasil. \\ 3,4 Departamento de Nutrição e Dietética. Instituto de Nutrição Josué de Castro. Universidade Federal do Rio de Janeiro. Rio de Janeiro, RJ, Brasil.
}

\begin{abstract}
Objectives: to identify factors associated with non-use of iron supplements (IS) by pregnant women attending National Health System (SUS) prenatal care in the Municipality of Rio de Janeiro.

Methods: a cross-sectional study was conducted in 2007/2008 with a representative sample of pregnant women using SUS hospitals and basic care in the Municipality of Rio de Janeiro. The group that had gestational age of $\geq 20$ weeks at the time of the interview and who had been prescribed IS ( $n=1407)$ was subjected to a Poisson multiple regression model to estimate the association between use and independent variables.

Results: of the 1407 pregnant women, 65\% reported use of IS. Younger age, black skin/race, larger number of births, not having received guidance on use of IS, not having tried to obtain IS at the SUS (with a stronger association between pregnant women with lower levels of education and lower household assets indicator - HAI) and not having been able to obtain them at the SUS (among pregnant women with lower HAI) were significantly associated with non-use.

Conclusions: the guidance of health professionals regarding use of IS and their regular availability may increase adherence to prescription among pregnant women and prevent iron deficiency anemia.

Key words Anemia, Anemia, iron-deficiency, Ferrous sulfate, Prenatal care, Pregnancy,
\end{abstract} Epidemiologic factors 


\section{Introduction}

Among pregnant women and women of reproductive age, iron supplements have been seen by the World Health Organization (WHO) as a way of supplementing the most widely applied micronutrient in a country, with significant success. However, the prevalence of anemia in these populations is still high. ${ }^{1}$

Estimates and intervals of the prevalence of anemia among pregnant women around the world between 1995 and 2011 were 43\% (CI95\%: 39 47\%) and 38\% (CI95\%: 34 - 43\%) respectively, without evidence of substantial improvement over these sixteen years. ${ }^{2}$

When present in the first or second trimester of gestation, anemia is associated with preterm birth and low birth weight 3 and, in moderate to severe forms, increases the likelihood of the birth of children who are small for gestational age (SGA). ${ }^{4}$ Such outcomes are widely associated with higher neonatal mortality. 5

The concentration of hemoglobin is the most commonly used indicator of anemia at population level, as it is reliable, inexpensive and relatively easy to obtain. Despite the various causes of anemia, its prevalence has frequently been used as a proxy for iron deficiency anemia, which accounts for around $50 \%$ of cases. 6

It is known that routine iron supplementation among pregnant women is effective in increasing the concentration of hemoglobin in the third trimester of gestation, childbirth and postpartum, in reducing the risk of anemia, iron deficiency, iron deficiency anemia and low birth weight, 3 and it is recommended in locations where iron deficiency is one of the major causes of anemia. 6

In Brazil, it is estimated that $29.6 \%$ of women of reproductive age are anemic ${ }^{7}$ and a high proportion of pregnant women have been identified as having a diet poor in iron. 8,9 The Ministry of Health thus recommends supplementation with iron sulfate after the $20^{\text {th }}$ week of gestation. 10 Through the National Pharmaceutical Care Policy, the funding norms for such care within the National Health System (SUS), the National Report on Essential Medicines, and other legal tools, States and Municipalities are responsible for the whole process of acquisition and distribution of this medication, ensuring free access for pregnant women in receipt of an SUS prescription. ${ }^{11}$

The low adherence of pregnant women to the use of iron supplements (IS) is one of the main obstacles to the effectiveness of such action.12,13
Studies with pregnant women in developed and developing countries have identified the following factors associated with less frequent use of IS: younger age, 14,15 black race/skin color, 16,17 low level of education 17-21 and income, ${ }^{16,21}$ unemployment, 14 being single without a partner at the start of gestation, 20 multiparity, $14,15,22$ fewer prenatal consults, 13,15,18,22 inadequate prenatal care (in terms of start of prenatal care and number of consults), 19 presence of side-effects of supplementation, 13,21,2325 lack of guidance on use of supplements, 24,25 lack of knowledge of the importance of iron intake13,24,25 and iron supplementation during pregnancy, ${ }^{21}$ not having been diagnosed with anemia during pregnancy 15,24 and unavailability of free supplements in sufficient quantities. $18,21,23,25$

Studies of this subject have already been conducted in two Brazilian cities: one in the State of São Paulo20 and another in the State of Rio Grande do Sul.22 However, pregnant women in other States also need to be the target of studies, with a view to comparing findings and identifying important factors for adherence to prescription of IS in diverse Brazilian settings.

The present study aims to identify demographic, socioeconomic, obstetric, and prenatal care structure and processes factors associated with non-use of iron supplements by pregnant women attending low-risk prenatal sessions within the SUS network of the Municipality of Rio de Janeiro.

\section{Methods}

A cross-sectional study was conducted with a representative sample of pregnant women attending lowrisk prenatal sessions at basic care units (BCUs) and hospitals within the SUS network of the Municipality of Rio de Janeiro, obtained by way of a two-stage conglomerate sampling plan. In the first stage, a simple random selection was carried out of $40 \%$ of eligible BCUs $(n=26)$ and hospitals $(n=5)$ and then the systematic selection of pregnant women, according to order of exit from prenatal consults, until completion of a pre-agreed sample for each health establishment.

The sample size $(n=2,187)$ was established on the basis of a level of significance of $5 \%$, a proportion of $50 \%$, a margin of error of $2.5 \%$, corrected for a finite population $(25,208$ prenatal consults/month) and for the design effect (1.5). The allocation of the sample was proportionate to the monthly mean number of prenatal consults in each stratum and divided, within the strata, by the number of units sampled: $63 \%$ for BCUs ( $\mathrm{n}=53$ per $\mathrm{BCU}), 35 \%$ for 
hospitals ( $\mathrm{n}=153$ per hospital) and $2 \%$ for Birth Houses ( $\mathrm{n}=44)$. The Birth House was excluded from the analysis for inclusion of the design effect, leaving a sample of 2,143 pregnant women.

The interviewing tool was tested in a pilot study. Data collection (interview and photocopy of prenatal card) was carried out between November 2007 and May 2008 by a trained team comprising six supervisors and 36 interviewers. The completed questionnaires went through three stages of review and were typed in duplicate into the database management program (Microsoft Access ${ }^{\circledR}$ ).

The pregnant women who declined to participate in the interview and prenatal card photocopying stages $(n=142)$ were asked if they could give their age and level of schooling. According to the MannWhitney non-parametric test, these did not differ (in terms of these characteristics) from the pregnant women who agreed to participate in the study, with $5 \%$ significance. The decliners $(6.6 \%)$ were replaced in the sample. The method used for this study has been described in greater detail in a previous publication. 26

The present study included pregnant women who, at the time of the interview, had a gestational age (GA) of $\geq 20$ weeks (a group for which the Ministry of Health recommends prophylactic iron supplementation) 10 and who reported receipt of a prescription for use of IS. Women who self-identified as of Asian or indigenous race were excluded, owing to the low level of representation of these groups in the sample $(2.4 \%)$.

The GA (full weeks) was calculated using the date of the last menstruation (DLM) and ultrasound information (USG) available on the card, with preference being given to USG only when carried out at GA $\leq 12$ weeks, with a discrepancy of more than one week between the GA obtained based on DLM and USG. In the absence of either of these, the GA registered by the prenatal clinic was used and, if this too was unavailable, the pregnant woman was excluded from the analysis $(n=22)$. The women with and without information on GA did not differ in relation to age and level of schooling, according to the Mann-Whitney test, given a level of significance of $5 \%$.

The relative frequency and $95 \%$ confidence interval (CI) of pregnant women was presented for demographic, socioeconomic and obstetric variables [age (adolescents: $<20$ years/ adults: $\geq 20$ years), race/skin color (white/black/mixed), schooling (low: $<8$ years/ high: $\geq 8$ years), employment situation (in paid work/without paid work), marital status (lives with partner/does not live with partner), number of people in household (1 - 3 people/ 4 or more people), household assets indicator (HAI) (based on the presence of ten assets: radio, fridge/freezer, television, landline telephone, washing machine, private car, microwave, computer, DVD player and air-conditioner) (low: $\leq 1 /$ high: $>1),{ }^{27}$ parity $(<1 / \geq 1)$, gestational age at start of prenatal care $(<17$ weeks $/ \geq 17$ weeks) and report of nausea, emesis or pyrosis as a health problem causing discomfort during pregnancy (yes/no)]; prenatal care structure [obtained supplement from SUS network (tried to obtain and was able to/tried to obtain and was unable to/did not try to obtain)] and prenatal care process [adequate number of prenatal consults, according to GA at time of interview (yes/no), record of IS prescription on card (yes/no), correct guidance on use of IS (one hour before meals - yes/no), ${ }^{10}$ some guidance on use of IS - whether or not in accordance with Ministry of Health norms (yes/no), reported diagnosis of anemia ("During prenatal care, did the doctor or nurse say that you had anemia?" - yes/no) and diagnosis of anemia according to record of test result on prenatal card (hemoglobin $<11 \mathrm{~g} / \mathrm{dL}$ - yes/no) ${ }^{10}$ ].

The prevalence of use of IS among the pregnant women and CI95\% was estimated on the basis of the question: "Are you taking iron sulfate or another iron medicine?".

As the outcome of interest is not rare, simple Poisson regression models with robust variance were conducted to estimate the intensity of associations between the dependent variable (non-use of ISyes/no) and the aforementioned independent variables. ${ }^{28}$ Estimates of the raw prevalence ratio (PR) and $\mathrm{CI} 95 \%$ were then obtained. Interactions between age and race/skin color, as previously described by Jasti et al.17 and among categories relating to obtaining the supplement within the SUS network and schooling, HAI and employment situation were tested. These have not yet been described in the literature.

Multiple Poisson regression models were then carried out, with the dependent and independent variables and significant interactions in the simple Poisson regressions, taking the level of significance to be $20 \%$. Significant independent variables and interactions remained in the final model to explain non-use of IS (with a level of significance of 5\%), and the adjusted PR and CI95\% estimates were calculated.

The adequacy of the final multiple model was confirmed by analysis of the presence of influential points using Cook's Distance, taking an observation to be influential if it has a Cook Distance value greater than or equal to one. 29 The graph of standar- 
dized residuals identified observations with a greater residual and estimated that around $95 \%$ of the residuals lay between \pm 2 (as expected when the residuals follow an approximately normal distribution). The most influential observations were examined and the effect of their exclusion on the adjusted association estimates evaluated.

For statistical analysis, each element of the sample was weighted according to the inverse of its probability of selection and calibrated to retain the known distribution of prenatal consults. The analyses were conducted using $R$ version 2.15 .3 software.

The study was approved by the Research Ethics Committees of ENSP-Fiocruz ( $\mathrm{n}^{\circ}$ 142/06) and SMS$\mathrm{RJ}\left(\mathrm{n}^{\circ} 145 \mathrm{~A} / 2007\right)$. There are no conflicts of interests relating to the methods used as part of the investigation or financial interests of the researchers.

\section{Results}

Of the sample selected $(n=2,148), 73.1 \%$ of pregnant women met the criteria for being included in this analysis. Of these, 1,409 (89.6\%; CI95\%: 84.3\% $93.3 \%$ ) reported that IS was prescribed during prenatal care. Two pregnant women did not provide information on use of IS and the sample analyzed by this study was reduced to 1,407 pregnant women.

Most of these were adults (75.9\%), of mixed race $(49.7 \%)$, with eight or more years of schooling (67.7\%), without paid work (66.9\%), living with a partner $(77.8 \%)$, with 1 to 3 people living in the household $(54.2 \%)$, with an HAI greater than one $(55.0 \%)$ and already one or more childbirths (55.2\%) and had begun prenatal care prior to the 17 th week of gestation $(66.3 \%)$. Nausea, emesis or pyrosis were reported as a health problem by $7.9 \%$ of the pregnant women (Table 1).

As for the structure of prenatal care, $55.4 \%$ of the pregnant women tried to obtain IS within the SUS network and succeeded in doing so. In terms of the care process, most pregnant women had an adequate number of prenatal consults $(80.4 \%)$, had no record of prescription of IS on their medical card $(93,1 \%)$, did not receive correct guidance on use of the supplement $(62.7 \%)$, but received some kind of guidance on its use $(97.0 \%)$. Eighteen percent of the pregnant women were diagnosed with anemia, according to the records of hemoglobin exam results on the card, while $35.9 \%$ reported diagnosis of anemia during pregnancy (Sensitivity $=0.82$; Specificity $=0.71 ;$ Kappa $=0.36)($ Table 1$)$.

The use of IS during pregnancy was reported by 920 women (65.4\%; CI95\%: 59.7\% - 70.6\%). Non- use of IS was found to be positively associated, with a level of significance of $20 \%$, with: younger age, black race/skin color or mixed race, $<8$ years schooling, no paid work, parity $\geq 1$, having tried but not succeeded in obtaining the supplement within SUS or not having tried to obtain it within SUS, inadequate number of prenatal consults, no record of prescription of supplement on card, not having received correct guidance or any guidance on use of IS and not reporting diagnosis of anemia during pregnancy. The interactions between categories for obtaining the supplement within the SUS, schooling and HAI were significant at a level of $20 \%$ (Table 2 ).

The best model tested in multiple Poisson regression to explain non-use of IS was the one that included age, race/skin color, parity, receipt of some guidance on use of IS, obtaining the supplement within the SUS and interactions between the variable categories relating to obtaining the supplement within the SUS, schooling and HAI, significant at a level of $5 \%$, and the main effects of the schooling and HAI variables (Table 3 ).

Adjusted analysis of factors associated with nonuse of IS during pregnancy (without excluding influential points) found that, for every increase of one year in age, the pregnant women showed a prevalence of non-use of the supplement $1.7 \%$ lower than that of the women exactly one year younger.

Black women had a $24.5 \%$ greater prevalence of non-use of IS than white women. This association was not significant, at a level of $5 \%$, for mixed race, compared to whites.

Women with one or more childbirths had a prevalence of non-use of supplement $16.5 \%$ greater than nulliparous women. Those who received no guidance on use of IS had a prevalence of non-use $73.9 \%$ greater than those who did.

Of the women with a high level of education and high HAI, those who did not try to obtain the supplement within the SUS had a prevalence of non-use of IS 1.72 times greater than those who tried to obtain the supplement within the SUS and succeeded. The strength of this association was even greater in the groups of women with high level of schooling but low HAI $(\mathrm{PR}=2.369)$ and those with low level of schooling and either high $(\mathrm{PR}=2.967)$ or low $(\mathrm{PR}=$ 2.829) HAI.

For women with high HAI, having tried but not succeeded in obtaining IS within the SUS was not significantly associated with non-use. Of those with low HAI, both with high and low level of schooling, the women who tried to obtain the supplement within the SUS and did not succeed had prevalences of non-use significantly higher than those who tried 
to obtain the supplement within the SUS with success $(\mathrm{PR}=1.642$ and $\mathrm{PR}=2.043$, respectively), with the strongest association in the group with lowest level of schooling.

Analysis of Cook's Distance and Standardized Residuals (Figure 1) showed the adjusted model to be adequate. Exclusion of the most influential observation $\left(n^{0} 370\right)$ increased the strength of association between not having received any guidance on use of IS and having tried and failed to obtain the supplement within the SUS and non-use (in the group of women with low HAI and high level of schooling) and made these associations statistically more significant (Table 3). Observation $n^{0} 370$ corresponded to a 27-year-old multiparous pregnant woman of mixed race, with low HAI and high level of schooling, who had not received guidance on use of IS, had tried but failed to obtain the supplement within the SUS and reported having used the supplement. Exclusion of observation $\mathrm{n}^{\circ} 374$ (the second most influential observation) did not cause significant changes in the coefficients or in the selection of variables significantly associated with the outcome of interest and is not therefore presented.

\section{Table 1}

Demographic, socioeconomic, obstetric, care structure and care process characteristics of prenatal nutritional care provided by the Brazilian National Health System (SUS) for pregnant women with gestational age (GA) $\geq 20$ weeks in receipt of a prescription for use of iron supplementation (IS). Rio de Janeiro - RJ, 2007/2008.

\begin{tabular}{|c|c|c|c|}
\hline Variables & $\mathbf{N}$ & $\%$ & $\mathrm{Cl} 195 \%$ \\
\hline \multicolumn{4}{|l|}{ Age $(n=1407)$} \\
\hline Adolescents & 339 & 24.1 & $20.5-28.0$ \\
\hline Adults & 1068 & 75.9 & $72.0-79.5$ \\
\hline \multicolumn{4}{|l|}{ Race/skin color $(n=1407)$} \\
\hline White & 354 & 25.1 & 22.7-27.7 \\
\hline Black & 353 & 25.1 & $22.1-28.4$ \\
\hline Mixed & 700 & 49.8 & $47.1-52.4$ \\
\hline \multicolumn{4}{|c|}{ Education (years of schooling) $(n=1407)$} \\
\hline$<8$ & 455 & 32.3 & $28.6-36.2$ \\
\hline$\geq 8$ & 952 & 67.7 & $63.8-71.4$ \\
\hline \multicolumn{4}{|l|}{ Employment situation $(n=1407)$} \\
\hline In paid work & 466 & 33.1 & $29.7-36.8$ \\
\hline Without paid work & 941 & 66.9 & $63.2-70.3$ \\
\hline \multicolumn{4}{|l|}{ Marital status $(n=1407)$} \\
\hline Lives with partner & 1094 & 77.8 & $73.6-81.5$ \\
\hline Does not live with partner & 313 & 22.2 & $18.5-26.4$ \\
\hline \multicolumn{4}{|c|}{ Number of people in household $(n=1407)$} \\
\hline 1 - 3 people & 763 & 54.2 & $50.7-57.7$ \\
\hline 4 or more people & 644 & 45.8 & $42.3-49.3$ \\
\hline \multicolumn{4}{|c|}{ Household Assets indicator $(n=1407)$} \\
\hline$\leq 1$ & 634 & 45.0 & $37.8-52.5$ \\
\hline$>1$ & 773 & 55.0 & $47.5-62.2$ \\
\hline \multicolumn{4}{|l|}{ Parity $(n=1407)$} \\
\hline$<1$ & 630 & 44.8 & $40.8-48.8$ \\
\hline$\geq 1$ & 777 & 55.2 & $51.2-59.2$ \\
\hline \multicolumn{4}{|c|}{ Gestational age at start of prenatal care (weeks) $(n=1380)$} \\
\hline$<17$ & 916 & 66.3 & $62.5-70.0$ \\
\hline$\geq 17$ & 464 & 33.7 & $30.0-37.5$ \\
\hline \multicolumn{4}{|c|}{ Report of nausea, emesis or pyrosis $(n=1407)$} \\
\hline No & 1297 & 92.1 & $90.3-93.6$ \\
\hline Yes & 110 & 7.9 & $6.4-9.7$ \\
\hline
\end{tabular}


Table 1

concluded

Demographic, socioeconomic, obstetric, care structure and care process characteristics of prenatal nutritional care provided by the Brazilian National Health System (SUS) for pregnant women with gestational age (GA) $\geq 20$ weeks in receipt of a prescription for use of iron supplementation (IS). Rio de Janeiro - RJ, 2007/2008.

\begin{tabular}{|c|c|c|c|}
\hline Variables & $\mathbf{N}$ & $\%$ & $\mathrm{Cl} 95 \%$ \\
\hline \multicolumn{4}{|l|}{ Obtained IS within SUS network $(n=1407)$} \\
\hline Successfully tried to obtain IS within SUS network & 779 & 55.4 & $38.5-71.1$ \\
\hline Unsuccessfully tried to obtain IS within SUS network & 385 & 27.3 & 20.3-35.7 \\
\hline Did not try to obtain IS within SUS network & 243 & 17.3 & $8.9-30.9$ \\
\hline \multicolumn{4}{|l|}{ Adequate number of prenatal consults $(n=1394)$} \\
\hline Yes & 1121 & 80.4 & $76.5-83.8$ \\
\hline No & 273 & 19.6 & $16.2-23.5$ \\
\hline \multicolumn{4}{|l|}{ Record of prescription of IS on card $(n=1392)$} \\
\hline Yes & 97 & 6.9 & 3.1-14.7 \\
\hline No & 1295 & 93.1 & $85.3-96.9$ \\
\hline \multicolumn{4}{|l|}{ Correct guidance on use of IS $(n=1407)$} \\
\hline Yes & 524 & 37.3 & $32.3-42.5$ \\
\hline No & 883 & 62.7 & $57.5-67.7$ \\
\hline \multicolumn{4}{|l|}{ Some guidance on use of IS $(n=1407)$} \\
\hline Yes & 1365 & 97.0 & $95.9-97.8$ \\
\hline No & 42 & 3.0 & $2.2-4.1$ \\
\hline \multicolumn{4}{|l|}{ Diagnosis of anemia reported $(n=1407)$} \\
\hline Yes & 504 & 35.9 & $31.9-40.0$ \\
\hline No & 903 & 64.1 & $60.0-68.1$ \\
\hline \multicolumn{4}{|c|}{ Diagnosis of anemia according to prenatal card record $(n=893)$} \\
\hline Yes & 160 & 18.0 & $14.8-21.6$ \\
\hline No & 733 & 82.0 & $78.4-85.2$ \\
\hline
\end{tabular}

Table 2

Non-adjusted analysis of factors associated with non-use of iron supplementation (IS) among pregnant women attending Brazilian National Health System (SUS) prenatal services, with gestational age (GA) $\geq 20$ weeks and in receipt of a prescription for IS use. Rio de Janeiro - RJ, 2007/2008.

\begin{tabular}{|c|c|c|}
\hline Variables & PR & $\mathrm{Cl} 195 \%$ \\
\hline Age $\dagger$ & $0.985 * *$ & $0.974-0.996$ \\
\hline \multicolumn{3}{|l|}{ Race/skin color ) } \\
\hline White & 1 & - \\
\hline Black & $1,259 * *$ & $1,021-1,554$ \\
\hline Mixed & $1,192 *$ & $0,965-1,473$ \\
\hline \multicolumn{3}{|l|}{ Education (years of schooling) } \\
\hline$<8$ & $1,265 * * *$ & $1,084-1,477$ \\
\hline$\geq 8$ & 1 & - \\
\hline \multicolumn{3}{|l|}{ Employment situation } \\
\hline In paid work & 1 & - \\
\hline Without paid work & $1,228 * * *$ & $1,096-1,375$ \\
\hline \multicolumn{3}{|l|}{ Marital status } \\
\hline Lives with partner & 1 & - \\
\hline Does not live with partner & 0,974 & $0,829-1,145$ \\
\hline \multicolumn{3}{|c|}{ Number of people in household } \\
\hline 1 - 3 people & 1 & - \\
\hline 4 or more people & 1,011 & $0,872-1,172$ \\
\hline
\end{tabular}


Non-adjusted analysis of factors associated with non-use of iron supplementation (IS) among pregnant women attending Brazilian National Health System (SUS) prenatal services, with gestational age (GA) $\geq 20$ weeks and in receipt of a prescription for IS use. Rio de Janeiro - RJ, 2007/2008.

\begin{tabular}{|c|c|c|}
\hline Variables & PR & $\mathrm{Cl} 195 \%$ \\
\hline \multicolumn{3}{|l|}{ Household Assets indicator } \\
\hline$\leq 1$ & 1,095 & $0,938-1,278$ \\
\hline$>1$ & 1 & - \\
\hline \multicolumn{3}{|l|}{ Parity $(n=1407)$} \\
\hline$<1$ & 1 & - \\
\hline$\geq 1$ & $1,089 *$ & $0,980-1,210$ \\
\hline \multicolumn{3}{|l|}{ Gestational age at start of prenatal care (weeks) } \\
\hline$<17$ & 1 & - \\
\hline$\geq 17$ & 1,038 & $0,869-1,240$ \\
\hline \multicolumn{3}{|l|}{ Report of nausea, emesis or pyrosis } \\
\hline No & 1 & \\
\hline Yes & 1,108 & $0,869-1,412$ \\
\hline \multicolumn{3}{|l|}{ Obtained IS within SUS network } \\
\hline Successfully tried to obtain IS within SUS network & 1 & - \\
\hline Unsuccessfully tried to obtain IS within SUS network & $1,575 * * *$ & $1,199-2,069$ \\
\hline Did not try to obtain IS within SUS network & $2,256 * * *$ & $1,710-2,976$ \\
\hline \multicolumn{3}{|l|}{ Adequate number of prenatal consults } \\
\hline Yes & 1 & - \\
\hline No & $1,380 * * *$ & $1,120-1,700$ \\
\hline \multicolumn{3}{|l|}{ Record of prescription of IS on card } \\
\hline Yes & 1 & - \\
\hline No & $1,395^{*}$ & $0,932-2,089$ \\
\hline \multicolumn{3}{|l|}{ Correct guidance on use of IS } \\
\hline Yes & 1 & - \\
\hline No & $1,092 *$ & $0,946-1,261$ \\
\hline \multicolumn{3}{|l|}{ Some guidance on use of IS } \\
\hline Yes & 1 & - \\
\hline No & $1,907 * * *$ & $1,461-2,489$ \\
\hline \multicolumn{3}{|l|}{ Diagnosis of anemia reported } \\
\hline Yes & 1 & - \\
\hline No & $1,118^{*}$ & $0,967-1,293$ \\
\hline \multicolumn{3}{|l|}{ Diagnosis of anemia according to prenatal card record } \\
\hline Yes & 1 & - \\
\hline No & 1,103 & $0,800-1,521$ \\
\hline
\end{tabular}

${ }^{*} p<0.20 ; * * p<0.05 ; * * * p<0.01 ; \dagger$ continuous variable; PR= Prevalence ratio.

Table 3

Adjusted analysis of factors associated with non-use of iron supplementation (IS) among pregnant women attending Brazilian National Health System (SUS) prenatal services, with gestational age (GA) $\geq 20$ weeks in receipt of a prescription for IS use. Rio de Janeiro - RJ, 2007/2008.

\begin{tabular}{lcc}
\hline Varibles & PR (Cl95\%) $(n=1407)$ & PR (CI95\%)• $(n=1406)$ \\
\hline Age $\dagger$ & $0.983(0.971-0.996)^{* *}$ & $0.983(0.971-0.996) * *$ \\
Race/skin color & 1 & 1 \\
White & $1.245(1.045-1.484)^{* *}$ & $1.243(1.045-1.478) * *$ \\
Black & $1.187(0.984-1.431)$ & $1.192(0.989-1.438)$ \\
Mixed & & \\
\hline
\end{tabular}

$* * p<0.05 ; * * * p<0.01 ; \dagger$ continuous variable; $\bullet$ Analysis adjusted after exclusion of most influential observation $\left(\mathrm{n}^{\circ}\right.$ 370); $\mathrm{HAl}=$ household asset indicator; $\mathrm{PR}=$ Prevalence ratio.

continue 
Table 3

concluded

Adjusted analysis of factors associated with non-use of iron supplementation (IS) among pregnant women attending Brazilian National Health System (SUS) prenatal services, with gestational age (GA) $\geq 20$ weeks in receipt of a prescription for IS use. Rio de Janeiro - RJ, 2007/2008.

\begin{tabular}{|c|c|c|}
\hline Varibles & PR $(C \mid 95 \%)(n=1407)$ & $\operatorname{PR}(\mathrm{Cl} 95 \%) \bullet(n=1406)$ \\
\hline \multicolumn{3}{|l|}{ Parity } \\
\hline$<1$ & 1 & 1 \\
\hline$\geq 1$ & $1.165(1.020-1.331) * *$ & $1.172(1.029-1.335) * *$ \\
\hline \multicolumn{3}{|l|}{ Some guidance on use of IS } \\
\hline Yes & 1 & 1 \\
\hline No & $1.739(1.195-2.528)^{* *}$ & $1.852(1.358-2.524) * * *$ \\
\hline \multicolumn{3}{|l|}{$\geq 8$ years of schooling and $\mathrm{HAl}>1$} \\
\hline Successfully tried to obtain IS within SUS & 1 & 1 \\
\hline Unsuccessfully tried to obtain IS within SUS & $1.376(0.978-1.936)$ & $1.375(0.977-1.935)$ \\
\hline Did not try to obtain IS within SUS & $1.725(1.292-2.303) * * *$ & $1.722(1.289-2.299) * * *$ \\
\hline \multicolumn{3}{|l|}{$<8$ years of study and $\mathrm{HAl}>1$} \\
\hline Successfully tried to obtain IS within SUS & 1 & 1 \\
\hline Unsuccessfully tried to obtain IS within SUS & $1.538(0.950-2.489)$ & $1.544(0.954-2.500)$ \\
\hline Did not try to obtain IS within SUS & $2.967(2.108 ; 4.175) * * *$ & $2.979(2.116-4.192) * * *$ \\
\hline \multicolumn{3}{|l|}{$\geq 8$ years of study and $\mathrm{HAI} \leq 1$} \\
\hline Successfully tried to obtain IS within SUS & 1 & 1 \\
\hline Unsuccessfully tried to obtain IS within SUS & $1.642(1.095-2.463) * *$ & $1.720(1.147-2.579) * * *$ \\
\hline Did not try to obtain IS within SUS & $2.369(1.722-3.258) * * *$ & $2.361(1.717-3.247) * * *$ \\
\hline \multicolumn{3}{|l|}{$<8$ years of study and $\mathrm{HAI} \leq 1$} \\
\hline Successfully tried to obtain IS within SUS & 1 & 1 \\
\hline Unsuccessfully tried to obtain IS within SUS & $2.043(1.496-2.790) * * *$ & $2.047(1.498-2.795) * * *$ \\
\hline Did not try to obtain IS within SUS & $2.829(1.928-4.151) * * *$ & $2.804(1.911-4.114) * * *$ \\
\hline
\end{tabular}

$* * p<0.05 ; * * * p<0.01 ; \dagger$ continuous variable; $\bullet$ Analysis adjusted after exclusion of most influential observation ( ${ }^{\circ}$ 370); $\mathrm{HAl}=$ household asset indicator; $\mathrm{PR}=$ Prevalence ratio.

Figure 1

Graphic analysis of adequacy of adjusted model of factors associated with non-use of iron supplementation among pregnant women attending Brazilian National Health System prenatal services. Rio de Janeiro - RJ, 2007/2008.

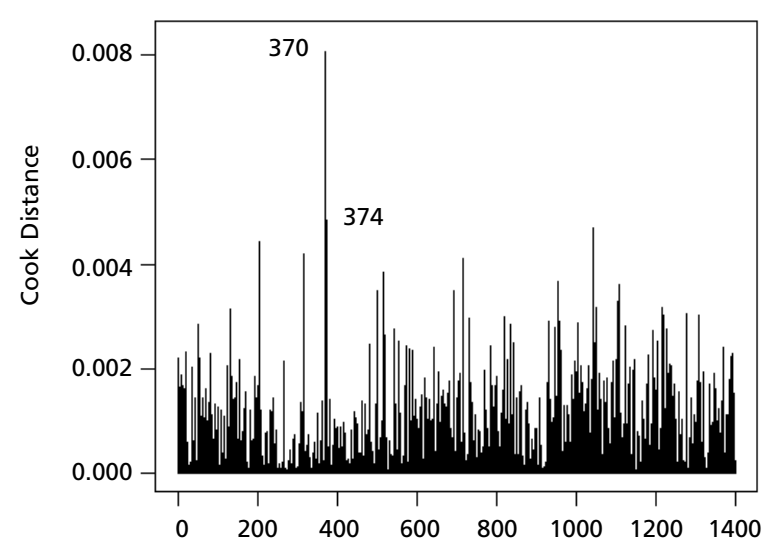

Observation number

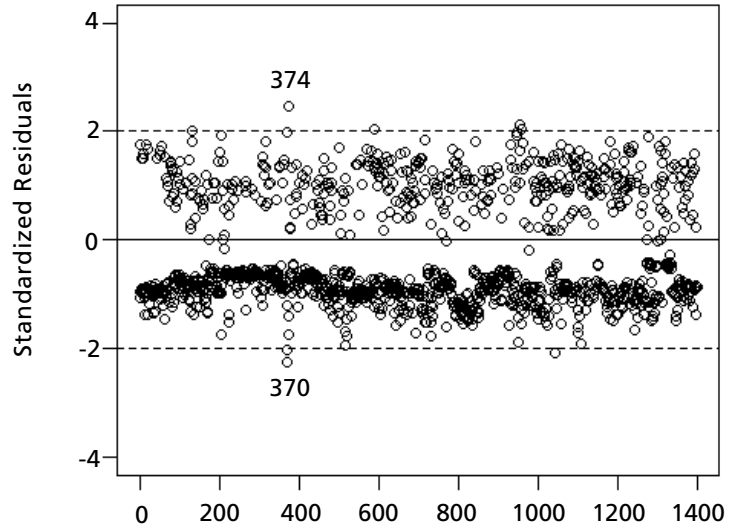

Observation number 


\section{Discussion}

Given the high prevalence of anemia among pregnant women ${ }^{7}$ and the adverse gestational outcomes associated with it, 3,4 as well as inadequate dietary intake of iron, 8,9 the estimate for IS use found in this study $(65 \%)$ falls far short of that envisaged by the Ministry of Health [which stipulates that every pregnant woman $(100 \%)$ should receive the iron supplement as of the $20^{\text {th }}$ week of gestation]. 10

Studies that have measured the use of iron supplement in a similar fashion have found similar prevalences (varying from 59\% to 68\%) among users of the SUS network prenatal service in the city of Jundiaí - SP - Brazil, 20 in a university hospital in Nigeria 21 and among childbearing women in the municipality of Rio Grande - RS - Brazil22 and in Cambodia. ${ }^{18}$ Lower figures were found in Tanzania $(22 \%)^{15}$ and higher ones in the United States (72\%), 16 Denmark (77\%), 14 Portugal (81.9\%) 19 and Sweden (85\%). 24

Authors who measured the use of iron supplement by other methods found a consumption of $74 \%$ of pills prescribed among low-income pregnant women in the United States 17 and $85 \%$ in the Philippines. 13 In Senegal, it was found that $58 \%$ of pregnant women used $70 \%$ or more of iron supplements prescribed 25 and, in Vietnam, the mean duration of use of the supplement was 4.8 months. 23

The discrepancies observed between the prevalences of use of the iron supplement may be associated with various factors, such as greater use among populations with higher levels of schooling and income, 16-21 who have more extensive prenatal care coverage 13,15,18,19,22 and better access to the supplement. 18,21,23,25 However, the different ways of measuring the use of iron supplements in the studies may also contribute to the variations observed. 12

Various indirect measures of adherence to iron supplementation have been used in scientific studies, 12 including counting the number of unused pills 13,17,25; self-reporting the period during which the supplement was taken, 23 the total or mean number of pills consumed per day/week/ month $13,14,18,25$ and the use of iron supplements as a dichotomous variable. $14-16,18,24$

All these measures have their limitations: (I) when counting unused pills, the missing pills were not necessarily consumed by the pregnant woman; (II) the self-reported number of pills used and months of use may not be accurate due to memory bias or overestimation; (III) the report of current consumption of the supplement does not necessarily indicate that the recommended dosage has been followed.12,13 This last limitation also affects the present study, so that the quantities of supplement used may be even less adequate.

As for factors associated with the use of IS during prenatal care, the present study revealed greater use of IS among older women, as observed in studies conducted in Denmark and Tanzania. ${ }^{14,15}$ It is possible that younger pregnant women are less well-informed and less concerned with health issues. Furthermore, younger age may also be associated with unplanned pregnancy (a variable not measured in the present study that has also been identified as negatively associated with use of the supplment ${ }^{14}$ ).

Two studies conducted in the United States 16,17 found an association between black race/skin color with lower use of IS. Jasti et al.17 controlled the effects of schooling (in the adjustment) and income (in the stratification), so that cultural issues and interactions between health professionals and pregnant women, among other factors such as social support, could be better studied in search of explanations for these findings.

One study with pregnant Brazilian women resident in Rio Grande - RS, also in 2007, indicated associations that are directly the opposite of those observed in the present study: lower prevalences of use of IS among adult and white women. One plausible explanation of this is that the services investigated were giving more attention regarding the use of supplements to pregnant women who have historically been identified as more vulnerable. 22

The association between multiparity and lower use of iron supplements is widely documented in the literature. 14,15,22 Pregnant women who have already been through one or more pregnancies may be less concerned about health in gestation, especially if they have experienced a pregnancy without complications. ${ }^{14}$ Another hypothesis is that women with children have more difficulty showing up to health services, which would explain the association between this variable and the lower number of prenatal consults. ${ }^{13}$

Studies carried out with pregnant Swedish and Senegalese women have shown that their perception of the importance accorded to IS by the health professional, 22 the receipt of advice on using the supplement and explanations regarding use were positively associated with adherence to treatment. 24,25

Such findings corroborate the observations of the present study. However, it is worrying that, although the health professional's advice makes it clear that he or she regards taking the supplement as important, guidance provided in an ineffective manner 
may compromise the effectiveness of treatment. Since the absorption of iron salts may be impeded by the formation of insoluble complexes of these with phytates and other elements present in the diet, it is recommended that ingestion of iron sulfate occur on an empty stomach, one hour before meals. 30

The multiple analysis of the present study, detecting interactions still not described in the literature between HAI, schooling and obtaining the supplement within the SUS, made it possible to investigate the greater complexity of this relation. Non-use of IS was significantly associated with not having obtained the supplement within the SUS (with a stronger association among pregnant women with lower levels of schooling and lower HAI) and not having succeeded in obtaining IS within the SUS (only among pregnant women with lower HAI).

The effect in isolation or combination of two of these three variables has already been reported in previous studies. The association between free, regular and good quality distribution of IS with greater adherence to use of the supplement has been widely documented in the literature. 18,23,25 A lower proportion of use of supplements containing iron has also been reported among women with lower income 16 or lower levels of schooling, 19 as well as

\section{References}

1. Branca F, Mahy L, Mustafa TS. The lack of progress in reducing anaemia among women: the inconvenient truth. Bull World Health Organ. 2014; 92: 231.

2. Stevens GA, Finucane MM, De-Regil LM, Paciorek CJ, Flaxman SR, Branca F, Peña-Rosas JP, Bhutta ZA, Ezzati M, Nutrition Impact Model Study Group (anaemia). Global, regional, and national trends in haemoglobin concentration and prevalence of total and severe anaemia in children and pregnant and non-pregnant women for 1995-2011: a systematic analysis of population-representative data. Lancet Glob Health 2013;1:e16-25.

3. Haider BA, Olofin I, Wang M, Spiegelman D, Ezzati M, Fawzi WW, Nutrition Impact Model Study Group (anaemia). Anaemia, prenatal iron use, and risk of adverse pregnancy outcomes: systematic review and meta-analysis. BMJ. 2013; 346: f3443.

4. Kozuki N, Lee AC, Katz J, Child Health Epidemiology Reference Group. Moderate to severe, but not mild, maternal anemia is associated with increased risk of smallfor-gestational-age outcomes. J. Nutr. 2012; 142 (2): 35862.

5. Medlock S, Ravelli ACJ, Tamminga P, Mol BWM, AbuHanna A. Prediction of mortality in very premature infants: a systematic review of prediction models. PLoS ONE. 2011; 6 (9): e23441.

6. World Health Organization (WHO), Centers for Disease an association between low level of schooling and less use of IS among pregnant women on a low income. 17,20 Multiple analysis has shown the loss of association between illiteracy and lower proportion of use of the supplement once the variable relating to the number of supplements received has been introduced into the model. 18

As for variables used as a proxy for income, pregnant Vietnamese women who received information by radio or television were significantly more likely to use IS, while knowledge of anemia did not produce this effect. The authors advance the hypothesis that this simplified "HAI" (restricted to radio and television) may provide important information on the economic situation of pregnant women, which is presumed to be related to adherence to treatment. 23

The observations of the present study show that regular availability in reasonable quantity of IS within the SUS, in addition to the provision of adequate guidance to raise awareness of the need to obtain it, may increase use of the supplement, with consequent prevention of the development of iron deficiency anemia among pregnant women and a reduction in adverse gestational outcomes.
Control and Prevention (CDC). Worldwide prevalence of anaemia 1993-2005: WHO global database on anaemia. Geneva: WHO; 2008.

7. Brasil. Ministério da Saúde. Pesquisa Nacional de Demografia e Saúde da Criança e da Mulher - PNDS 2006: dimensões do processo reprodutivo e da saúde da criança. Brasília, DF; 2009.

8. Barros DC, Perreira RA, Gama SGN, Leal MC. O consumo alimentar de gestantes adolescentes no município do Rio de Janeiro. Cad Saúde Pública. 2004; 20 (Suppl. 1): 121-9.

9. Sato APS, Fujimori E, Szarfarc SC, Borges ALV, Tsunechiro MA. Food consumption and iron intake of pregnant and reproductive aged women. Rev Lat Am Enfermagem. 2010; 18 (2): 247-54.

10. Brasil. Ministério da Saúde. Secretaria de Atenção à Saúde. Departamento de Atenção Básica. Cadernos de Atenção Básica, $n^{\circ} 32$. Atenção ao pré-natal de baixo risco. Brasília, DF; 2012.

11. Brasil. Ministério da Saúde. Gabinete do Ministro. Portaria $\mathrm{n}^{\mathrm{o}} 1.555$, de 30 de julho de 2013. Dispõe sobre as normas de financiamento e de execução do Componente Básico da Assistência Farmacêutica no âmbito do Sistema Único de Saúde (SUS). Diário Oficial da União. Brasília, DF 31 jul 2013; Seção 1, nº 146, página 71-72.

12. Galloway R, McGuire J. Determinants of compliance with iron supplementation: supplies, side effects, or psychology? 
Soc Sci Med. 1994; 39 (3): 381-90.

13. Lutsey PL, Dawe D, Villate E, Valencia S, Lopez O. Iron supplementation compliance among pregnant women in Bicol, Philippines. Public Health Nutr. 2008; 11 (1): 76-82.

14. Knudsen VK, Hansen HS, Ovesen L, Mikkelsen TB, Olsen SF. Iron supplement use among Danish pregnant women. Public Health Nutr. 2007; 10 (10): 1104-10.

15. Ogundipe O, Hoyo C, Østbye T, Oneko O, Manongi R, Lie RT, Daltveit AK. Factors associated with prenatal folic acid and iron supplementation among 21,889 pregnant women in Northern Tanzania: a cross-sectional hospital-based study. BMC Public Health. 2012; 12: 481

16. Cogswell ME, Kettel-Khan L, Ramakrishnan U. Iron supplement use among women in the United States: science, policy and practice. J. Nutr. 2003; 133 (6): 1974S$1977 \mathrm{~S}$.

17. Jasti S, Siega-Riz AM, Cogswell ME, Hartzema AG, Bentley ME. Pill count adherence to prenatal multivitamin/mineral supplement use among low-income women. J Nutr. 2005; 135 (5): 1093-101.

18. Lacerte P, Pradipasen M, Temcharoen P, Imamee N, Vorapongsathorn T. Determinants of adherence to iron/folate supplementation during pregnancy in two provinces in Cambodia. Asia Pac J Public Health. 2011; 23 (3): 315-23.

19. Lunet N, Rodrigues T, Correia S, Barros H. Adequacy of prenatal care as a major determinant of folic acid, iron, and vitamin intake during pregnancy. Cad Saúde Pública. 2008; 24 (5): 1151-7.

20. Rondó PHC, Fukushima CM, Moraes F. Vitamin-mineral supplement use by low-income Brazilian pregnant adolescents and non-adolescents and the predictors for non-use. Eur J Clin Nutr. 2006; 60 (9): 1108-14.

21. Ugwu EO, Olibe AO, Obi SN, Ugwu AO. Determinants of compliance to iron supplementation among pregnant women in Enugu, Southeastern Nigeria. Niger J Clin Pract. 2014; 17 (5): 608-12.
22. Cesar JA, Dumith Sde C, Chrestani MA, Mendoza-Sassi RA. Iron supplementation among pregnant women: results from a population-based survey study. Rev Bras Epidemiol. 2013; 16 (3): 729-36.

23. Aikawa R, Jimba M, Nguen KC, Zhao Y, Binns CW, Lee MK. Why do adult women in Vietnam take iron tablets? BMC Public Health. 2006; 6 (1): 144.

24. Wulff M, Ekström E-C. Iron supplementation during pregnancy in Sweden: to what extent is the national recommendation followed? Acta Obstet Gynecol Scand. 2003; 82 (7): 628-35.

25. Seck BC, Jackson RT. Determinants of compliance with iron supplementation among pregnant women in Senegal. Public Health Nutr. 2008; 11 (6): 596-605.

26. Niquini RP, Bittencourt SA, Leal MC. Conformidade da aferição de peso no pré-natal e concordância das informações antropométricas referidas pelas gestantes e registradas nos cartões de pré-natal, Município do Rio de Janeiro, 2007-2008. Rev Bras Epidemiol. 2013; 16 (3): 670-81.

27. Szwarcwald CL, Bastos FI, Esteves MAP. State of animus among Brazilians: influence of socioeconomic context? Cad Saúde Pública. 2005; 21 (Supl 1): 33-42.

28. Barros AJD, Hirakata VN. Alternatives for logistic regression in cross-sectional studies: an empirical comparison of models that directly estimate the prevalence ratio. BMC Med Res Methodol. 2003; 3: 21.

29. Cook RD, Weisberg S. Residuals and Influence in Regression. New York: Chapman \& Hall; 1982.

30. Cançado RD, Chiattone CS. Iron deficiency anaemia in the adult - causes, diagnosis and treatment. Rev Bras Hematol Hemoter. 2010; 32 (3): 240-6.

Received on november 12, 2015

Final version submitted on march 15, 2016

Approved on march 23, 2016 